\title{
Capacity Prediction Model Based on Limited Priority Gap-Acceptance Theory at Multilane Roundabouts
}

\author{
Zhaowei Qu, Yuzhou Duan, Xianmin Song, Hongyu Hu, Huanfeng Liu, and Kehan Guan \\ College of Transportation, Jilin University, Changchun 130022, China \\ Correspondence should be addressed to Xianmin Song; songxianmin0708@163.com
}

Received 9 July 2014; Accepted 25 July 2014; Published 26 August 2014

Academic Editor: Wuhong Wang

Copyright (C) 2014 Zhaowei Qu et al. This is an open access article distributed under the Creative Commons Attribution License, which permits unrestricted use, distribution, and reproduction in any medium, provided the original work is properly cited.

\begin{abstract}
Capacity is an important design parameter for roundabouts, and it is the premise of computing their delay and queue. Roundabout capacity has been studied for decades, and empirical regression model and gap-acceptance model are the two main methods to predict it. Based on gap-acceptance theory, by considering the effect of limited priority, especially the relationship between limited priority factor and critical gap, a modified model was built to predict the roundabout capacity. We then compare the results between Raff's method and maximum likelihood estimation (MLE) method, and the MLE method was used to predict the critical gaps. Finally, the predicted capacities from different models were compared, with the observed capacity by field surveys, which verifies the performance of the proposed model.
\end{abstract}

\section{Introduction}

Roundabouts are popular in recent years, according to statistics; there are over 2000 roundabouts in the US and Canada as of April 2010 [1]. And more and more scholars have paid their attention to roundabouts from different views, such as capacity, safety, and performance. Capacity is the maximum possible throughput of the traffic facility [2], and it is a determinant parameter for other performance measures, such as delay and queue. Thus, there are a lot of researches on this, especially on capacity model [3-8].

The entry capacity is the maximum throughput of the entry vehicles under specific geometric and traffic conditions. Until now, there have been lots of capacity models, which could fall into two categories: empirical regression model and gap-acceptance model [9]. According to previous analysis, the former has good applicability in locality but poor transferability, and its establishment needs mass data. AlMadani [10] established an empirical model during heavy demand conditions, which considered eight factors such as number of entry lanes and radius of central island, whilst the latter has a systematic and theoretical basis, but usually oversimplifies the field conditions, and is dependent on some assumptions (e.g., the headway distribution of the major road). Kimber [11] analyzed the gap-acceptance model in major-minor priority junction and summarized the merits and drawbacks of this method. Chung et al. [12] compared the capacity model in SR45 and SIDRA, which were both based on gap-acceptance theory. Considering the pseudo-conflicts, Fortuijn [13] revised the conflict volumes by introducing some proportion of exiting vehicles and derived a new gapacceptance model for turbo-roundabout. By modifying Raff's method, Guo and Lin [14] updated the capacity model on the basis of gap-acceptance theory.

In gap-acceptance theory, critical gap is one of the most important parameters, which impacts the predictive accuracy directly. And numbers of researchers have discussed the estimation methods and critical values from different aspects. Considering the punch size of the follow-up vehicles, Khatib [15] built a regression model for the critical gap by field data at multilane roundabouts. Flannery and Datta [16] used log-normal distribution to depict the gap-acceptance process and discussed the different distribution patterns. Besides, the probability method was used in the critical gap estimation at roundabout, and move-up times were collected according to the dominant entry lane and subdominant entry lane [3]. Some studies showed that the number of lanes has an influence on the performance [17-19]. Hainen [20] obtained the critical headway of roundabouts by means of wireless magnetometers. Abrams et al. [21] collected the spatial and 


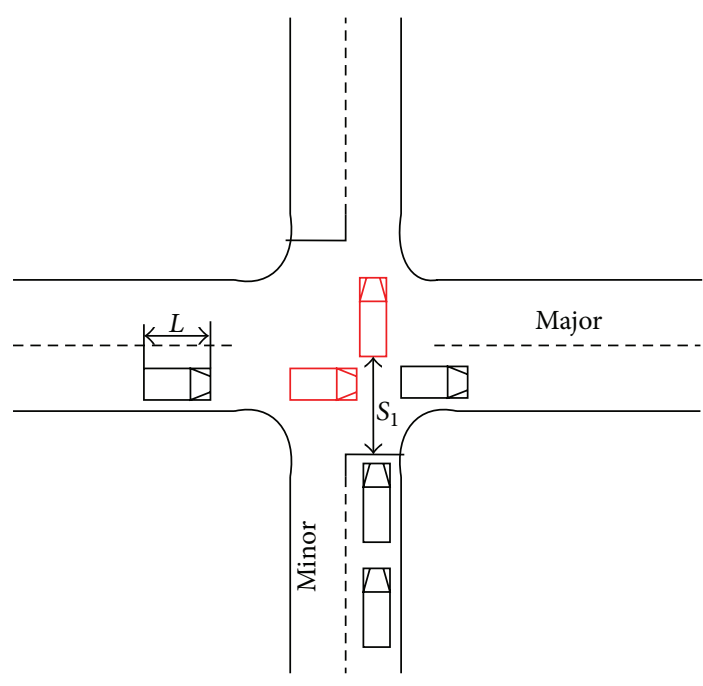

(a) TWSC intersection

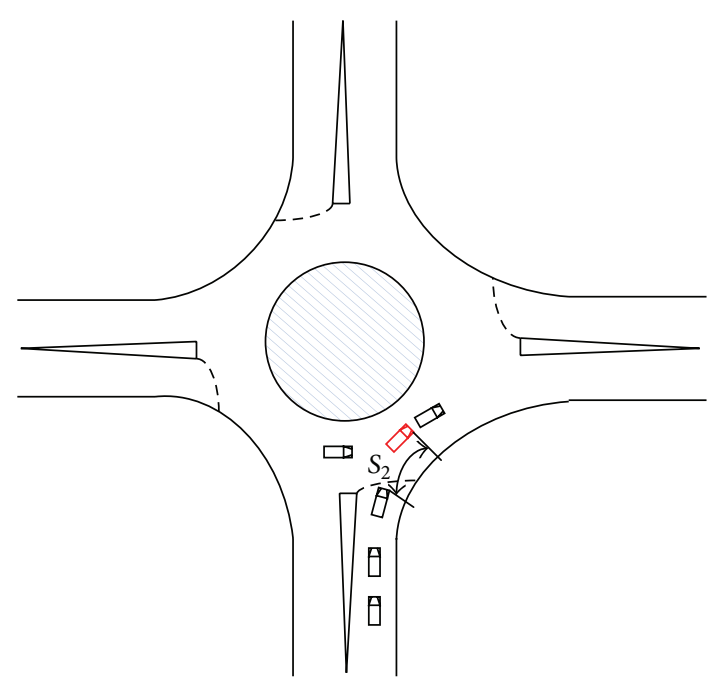

(b) Modern roundabout

FIGURE 1: Gap-acceptance process in the different type of intersections.

temporal headway and estimated the critical gap from these two aspects. Moreover, others considered the effect of the influence factors on critical gap. Considering the percentages of trucks, Lee [22] adjusted the critical gap and followup time by distinguishing different vehicles type, which is more accurate. Then an investigation was made as four-year period, it was found that the critical gap reduced because of higher driver familiarity [23]. Polus [24] put forward the critical gap model that considered the effect of waiting time at roundabouts and improved the entry capacity model. Xu and Tian $[25,26]$ found that the circulating flow rate and speed are the main factors influenced by the critical gap and followup time. And by data collecting at roundabouts, the result showed that the critical gap of the left-turning lane is larger than the right-turning lane's.

Under high flow conditions, some minor vehicles may force their way into the major streams; meanwhile the major vehicles would slow, which was named limited priority by Troutbeck [27]. And Troutbeck and Kako found that the limited priority merge has a significant effect on the entry capacity at two-lane roundabouts [28]. The limited priority term was derived. Ma et al. [29] also studied the limited priority merge in the major-minor intersections.

Although the studies on roundabouts overseas are quite a lot, it is still in its infancy in China. In recent years, more and more domestic scholars have studied the roundabouts, but the research was limited in a small range, that is, signal timing at roundabouts, and the operational characteristics at roundabouts. Wang et al. [30-32] discussed the capacity of roundabouts and provided some reference for future studies. Considering the limited priority in capacity prediction at modern multilane roundabouts and through analyzing the relation between limited priority factor and critical gap, the comprehensive effects of the two on capacity would be obtained. The headway distribution of the circulating lanes will be discussed by considering the limited priority. Then, combining the number of the circulating lanes, a new capacity model could be derived.
This paper is designed as follows. Section 2 introduces the gap-acceptance theory in the unsignalized intersections and the limited priority under high volume conditions. Then the relation analysis between the limited priority term and critical gap at roundabouts is discussed in Section 3. And the headway distribution of the circulating lanes is also discussed; then the capacity model is derived based on gap-acceptance theory. Following the estimation methods to the critical gap are compared in Section 4. Then the proposed model is compared with some classical capacity model and discussed with the field observations in Section 5. Finally, Section 6 gives the conclusions and points out the future works.

\section{Applicability Analysis of Fundamental Theories on Multilane Roundabouts}

This part mainly depicts two theories at roundabout, that is, gap-acceptance theory and limited priority theory. Combined with the operational characteristics of the multilane roundabouts, an applicability analysis was conducted to verify the suitability of the two theories.

2.1. Gap-Acceptance Theory at Roundabouts. Gap-acceptance theory was originally applied to traditional unsignalized intersections. Generally, there are major road and minor road for the two-way stop-controlled (TWSC) or two-way yieldcontrolled (TWYC) intersections. And the vehicles from the minor road enter the intersection during the gaps formed by the major streams. Because there are "give-way" rules at the roundabouts, it is analogous to the TWSC intersections. But the geometries of the roundabouts are different from traditional intersections, so it may have some difference in entry process, shown as in Figure 1.

As shown in Figure 1(a), the vehicles in the minor road need to cross over the major flows. But, in Figure 1(b), the entry vehicles only need to converge into the circulating streams, which is similar to the convergence behavior on the ramp. Assuming that the mean speed of vehicles at TWSC 


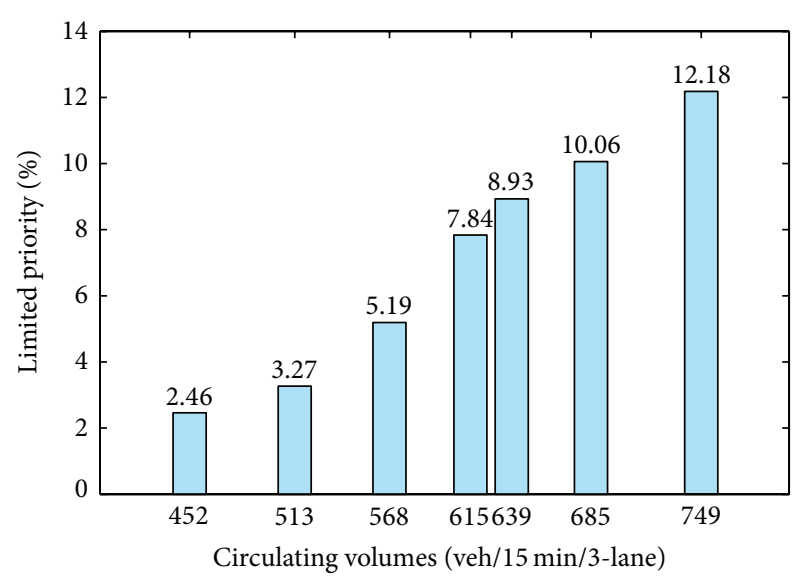

FIGURE 2: Limited priority percentage under different traffic status.

intersection is $v_{1}$ and the distance between stop line and conflict line is $S_{1}$, thus, the cross time is $\left(S_{1}+L\right) / v_{1}$ ( $L$ is the vehicle length). For the same analysis to modern roundabout, the entry time is $\left(S_{2}+L\right) / v_{2}\left(S_{2}\right.$ is the distance between stop line and merging point at roundabout, and $v_{2}$ is mean entry speed of vehicles at roundabout). Clearly, the difference in geometry leads to the different travel distance. Meanwhile, the entry speed from the stop line is different. Thus, the entry time of the two types of intersections is different. Of course, there will be inserting behaviors if there are two or more circulating lanes. Thus, at a micro level, the critical gap may have some differences, and it shows the necessity to calibrate parameters by field observations additionally.

2.2. Limited Priority at Roundabouts. Troutbeck proposed that the minor-stream vehicles forced the major-stream vehicles to slow in the high volumes, and it will occur in the roundabout by filed observations [28]. The results showed that the ratio of forced gap was more than $9 \%$ under high volumes and less than $3 \%$ under low ones. Because the drivers in different countries have different driving behaviors, a field survey is made in Changchun, China, consequently. The data were collected at a three-lane roundabout in Changchun city during peak hours. There are three circulating lanes in the roundabout, and the condition during survey period was normal. Fifteen-minute data sets were extracted for this analysis. If the circulating vehicles decelerate before the conflict area, there is a limited priority event. Summing up the statistic results, the percentages of the limited priority in different traffic status are obtained, as shown in Figure 2.

As can be seen from Figure 2, when circulating flow rate reach a certain degree, the percentage of limited priority will rise with the circulating volumes increasing. And from the field observation, it is found that there exist some adventurous drivers in Changchun city, which often forced the circulating vehicles to slow, even if the circulating flow rate is low. Although this verifies the existence of limited priority phenomenon, a comprehensive influence coefficient needs to be established, which can change with the varied conditions. To prove this phenomenon further, the speed and headway before and after merging were surveyed; the difference distribution could be obtained as shown in Figure 3. It is noted that the data were collected in one lane, and one is obtained in the upstream of the circulating lane; another is obtained in the merging area.

From Figure 3, it can be seen that the speed and headway between the upstream and merging area both have some changes. In Figure 3(a), the most of the speed difference centers on zero, and some are located on the right side. Similarly, the headway also has the same effect; however, it has left truncation. Both of them reflected that some vehicles in circulating lane slow before the merging area.

Above all, by analyzing and observing the multilane roundabout, applicability of limited priority gap-acceptance theory is verified.

\section{Capacity Modeling}

Considering the limited priority at multilane roundabouts, some parameters were analyzed in this part. Then combined with limited priority gap-acceptance theory, a modified model is derived.

3.1. Relation Analysis. From the above, it is known that the limited priority phenomenon existed in the roundabouts. By field observations, the limited priority percentage was obtained, but it did not suit accurate calculation and lacked portability for other roundabouts. Assuming that the upstream of the major stream obeys Cowan's M3 distribution, the model of limited priority term $(C)$ was derived by Troutbeck [27], as shown in (1). From this, $C$ is mainly determined by three parameters, that is, critical gap $\left(t_{c}\right)$, follow-up time $\left(t_{f}\right)$, and the minimum headway $(\tau)$. He also pointed that the limited priority will occur when the critical gap is less than the sum of follow-up time and the minimum headway. Among them, $t_{f}$ and $\tau$ are usually measured during the saturation periods, or the continuous queue occurs at the entry approach. But the critical gaps could not be measured directly, which is usually estimated with some estimation methods. And another parameter in (1) is $\lambda$, which depicts the intensity of proportion of free vehicles on the traffic flow in Cowan's M3 model, also named decay constant. In order to obtain the interrelations among these parameters, assume that the $t_{f}$ and $\tau$ are constant; then analyze the relations of other parameters based on (1), and we obtained the changes of $C$ with $\lambda$ and $t_{c}$. The result was shown as in Figure 4:

$$
C=\frac{1-e^{-\lambda t_{f}}}{\left[1-e^{-\lambda\left(t_{c}-\tau\right)}-\lambda\left(t_{c}-t_{f}-\tau\right) e^{-\lambda\left(t_{c}-\tau\right)}\right]},
$$

where $\lambda$ is decay constant, usually equal to $\alpha q /(1-\tau q)$, and $\alpha$ is the proportion of free vehicles.

In Figure 4 , the tendency of $C$ is varied with $\lambda$ and $t_{c}$. On the one hand, when $t_{c}$ is relatively large (of course, it will not exceed the sum of $t_{f}$ and $\tau$ ), the decrease of $C$ is not obvious. With the reduction of the $t_{c}$, the decrease tendency is more sharp. The smaller the $t_{c}$, the sharper the tendency. On the other hand, when $\lambda$ do not change, $C$ will rise with the $t_{c}$ depressed. 


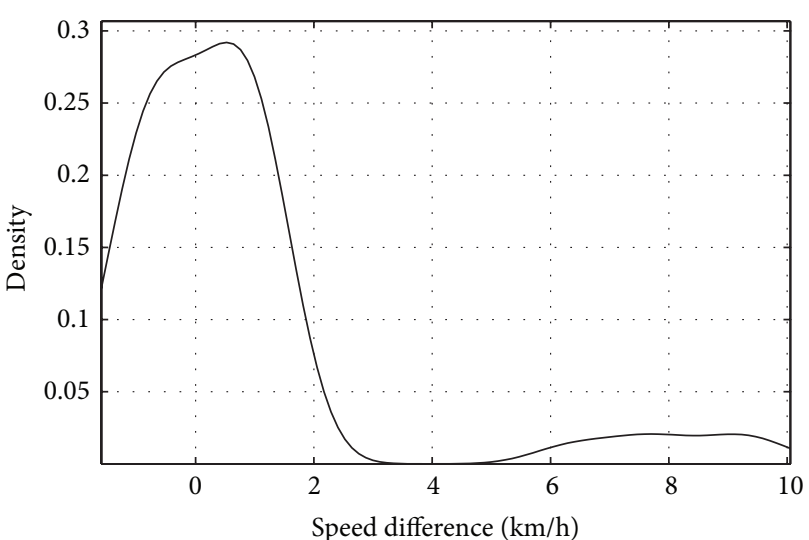

__ Upstream-merging

(a) Speed difference distribution

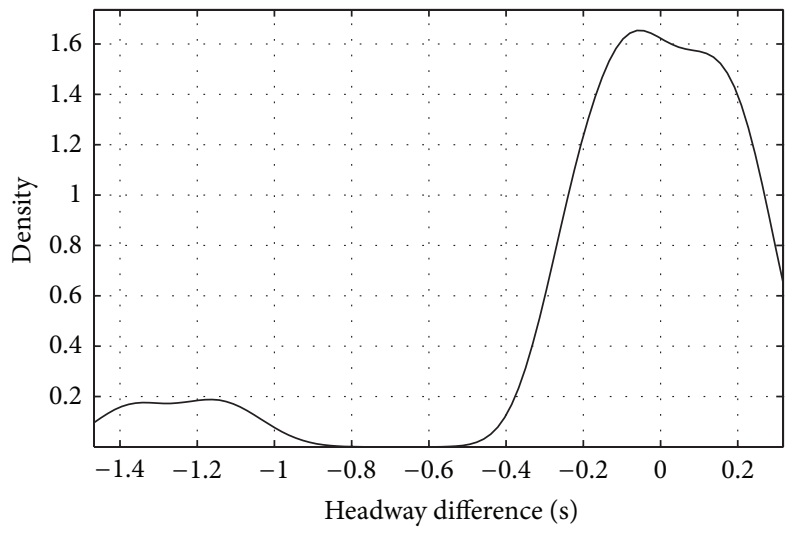

_ Upstream-merging

(b) Headway difference distribution

Figure 3: The difference distribution of speed and headway.

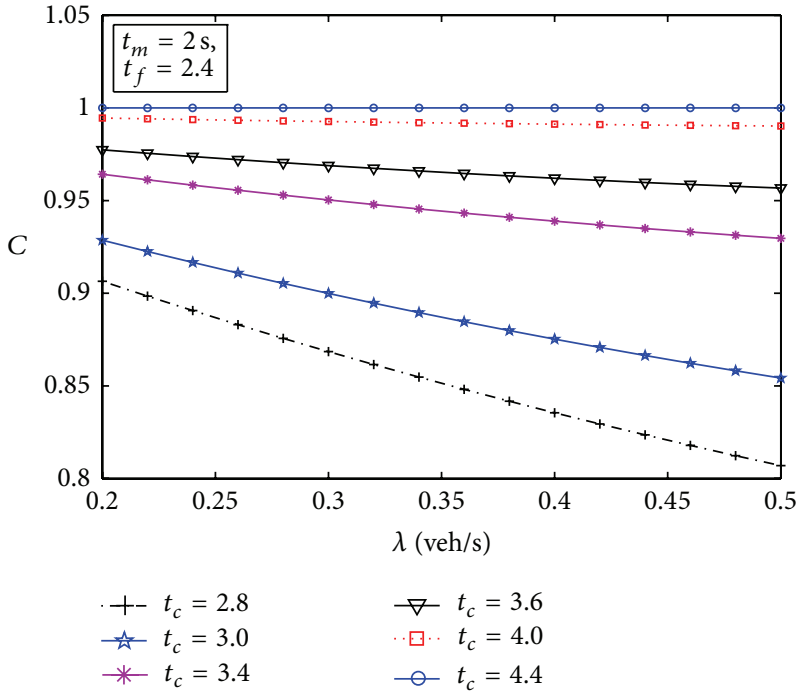

FIGURE 4: Limited factor varies with $\lambda$ and $t_{c}$.

With the limited priority factor, a corresponding capacity model of single lane was also put forward [27], as shown in the following:

$$
\operatorname{Cap}=\frac{\alpha C q e^{-\lambda\left(t_{c}-\tau\right)}}{1-e^{-\lambda t_{f}}},
$$

where Cap is capacity of single lane.

As can be seen from (2), there is a positive correlation between Cap and $C$ and a negative correlation between Cap and $t_{c}$, whereas $C$ varies from 0 to 1 , which reduces the original capacity. According to common sense, the capacity will raise considering the limited priority. In addition, $C$ is a function of $t_{c}$, as shown in (1). To obtain the comprehensive relations among these parameters, combined with the results of Figure 4, we studied the entry capacity with the changes of $t_{c}$; the result was shown in Figure 5. It can be seen that, in the

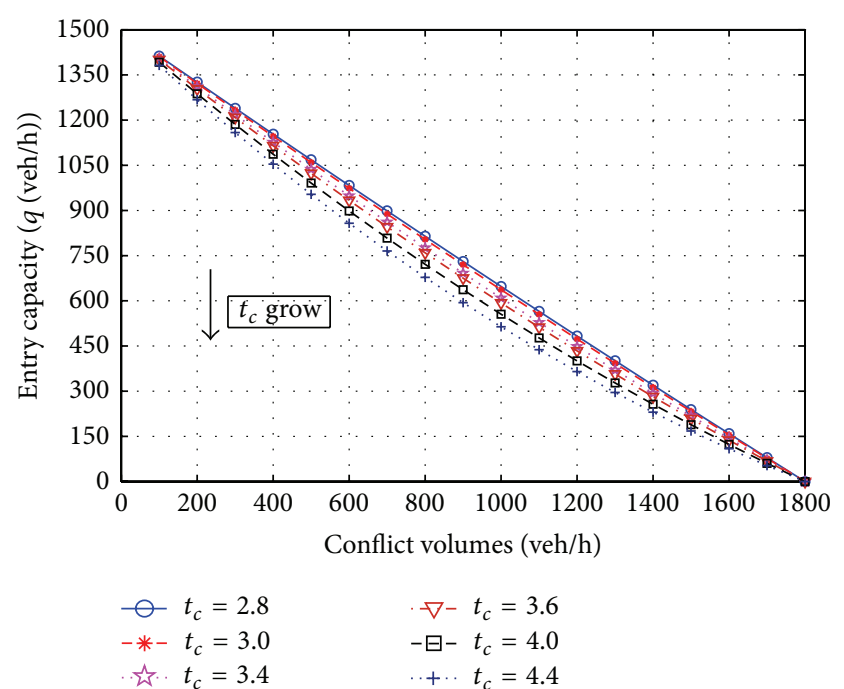

FIGURE 5: Entry capacity varies with the critical gap.

same conflicting volume, the entry capacity will reduce with the $t_{c}$ increasing. To analyze it further, if the limited priority is considered, the critical gap will reduce because of the forcing stream; thus even if the $C$ is less than 1 , the result of capacity will still increase. This result is consistent with the realities; thus Troutbeck's model was used in this paper.

3.2. Headway Distribution of Circulating Lanes. Headway distribution is as an important assumption in the gap-acceptance theory. Applying the different headway distribution models, the different prediction capacity will be obtained. Generally, the negative exponential distribution, the shifted-negativeexponential distribution, and Cowan's M3 distribution are the most popular models in traffic analysis. But the first two are applicable to free flows, and the last one is mainly applicable to the dichotomy flows. Though Cowan's M4 distribution is more accurate, some proposed that the more 


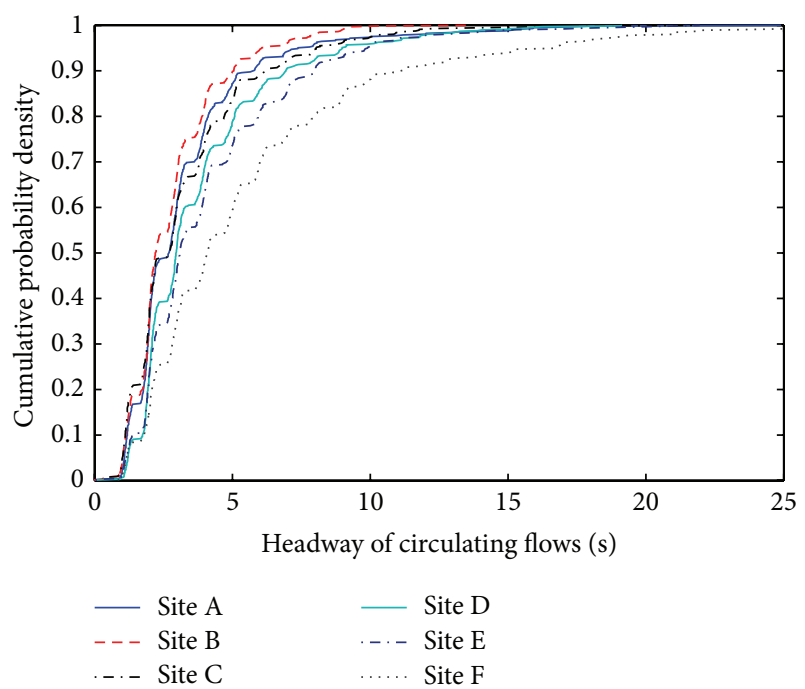

FIGURE 6: Cumulative probability density at the roundabout.

realistic headway distributions are not significantly more accurate. Luttinen [40] dissected the properties of Cowan's M3 distribution and detailed the estimation method to the parameters. Besides, Cowan's M3 distribution model has been proved a good performance at roundabouts. Hagring et al. [41] divided two types of Cowan's M3 distribution, M31 and M32, and found that M32 was closer to the real capacity of two-lane roundabouts. Giuffrè et al. [42] compared the performance between turbo-roundabout and double-lane roundabout, assuming that the headway of circulating lanes obeyed Cowan's M3 distribution. Xiang et al. [31] assumed the two flows as an equivalent flow and derived the approach capacity treating the vehicles of the left lane and right lane, respectively.

In this paper, considering the effect of limited priority, the circulating vehicles will decelerate, and the parameters of headway distribution may change. In order to obtain accurate headway distribution, an investigation was made to the multilane roundabouts in the high flows, and the cumulative probability curves are shown in Figure 6. The six different sites were selected, and all located at before the merging area.

If the circulating vehicles slow to cooperate on the forcing vehicles, the headway of circulating streams near the merging area will also change. Combined with the merging opportunity in the limited priority [27], Troutbeck derived the modified gap distribution model before the merging area, as shown in the following:

$$
F(t)=1-\alpha C e^{-\lambda(t-\tau)}, \quad t \geq \tau .
$$

There are many models to describe the proportion of free vehicles $(\alpha)[40,43,44]$, as shown in Table 1 . And it is determined mainly by the circulating volume $\left(q_{c}\right)$ and the minimum headway $(\tau)$. To show them more straightforward, Figure 7 is obtained as follows. From this figure, it can be seen that different models have different performance. When the traffic volume is $500 \mathrm{pcu} / \mathrm{h}$, the difference between Plank and

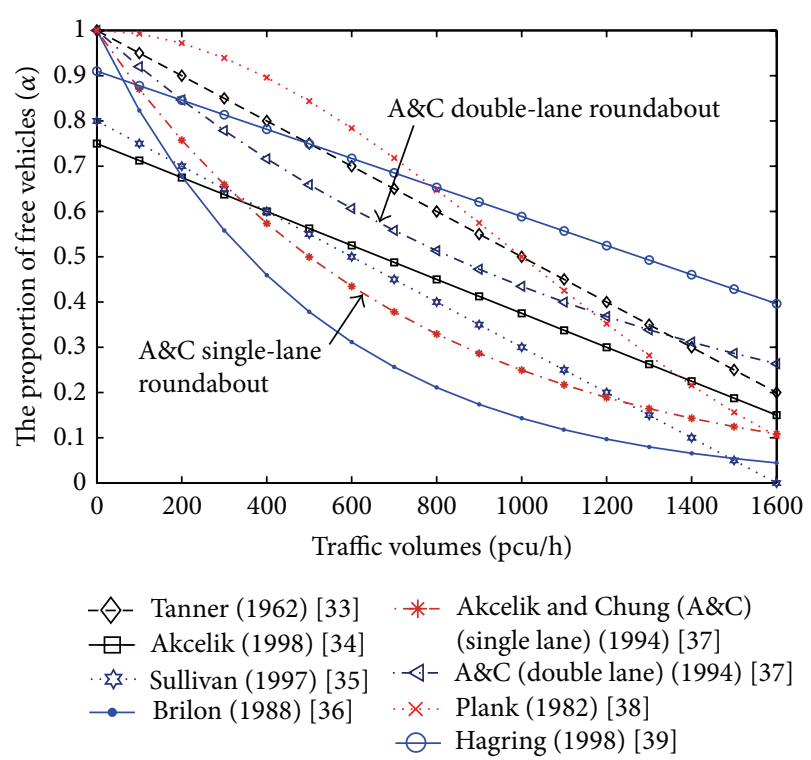

FIGURE 7: Comparisons of the different models of proportion of free vehicles.

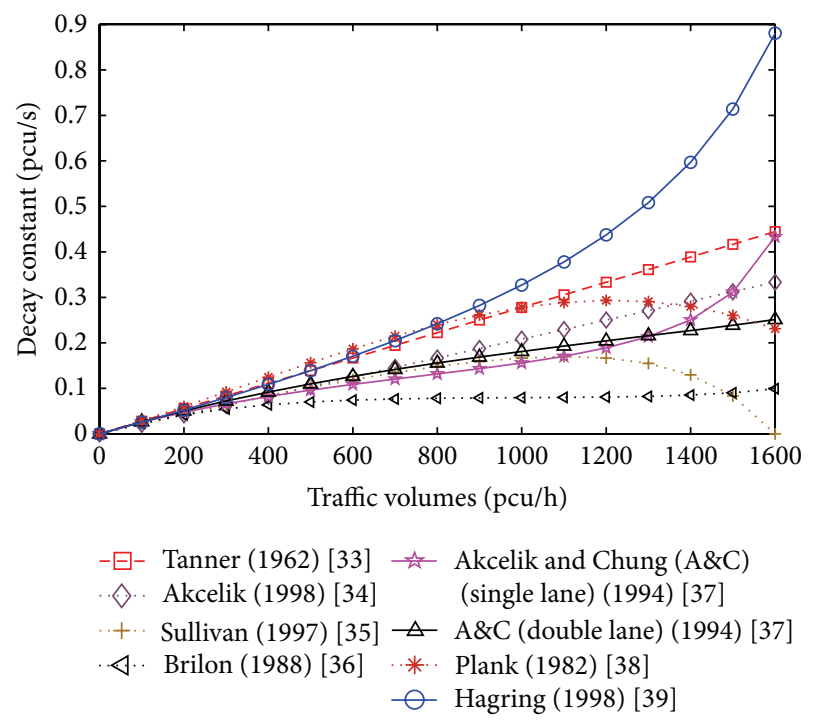

FIGURE 8: Comparisons of the different models of decay constant.

Brilon's result could reach 0.462 , and it will make the capacity larger in difference.

In Cowan's M3 distribution, the decay constant $(\lambda)$ is also an important parameter, indicating the intensity of proportion of free vehicles on the traffic flow. And it is generally expressed as $\alpha q_{c} /\left(1-\tau q_{c}\right)$. If different models of $\alpha$ are used, the $\lambda$ will also change. The variation of the $\lambda$ with the traffic flows is shown in Figure 8. Then, combined with Figures 7 and 8, Troutbeck's model was selected in the following research.

By field observation, the modified Cowan M3 distribution could be used to fit the headway distribution before the merging area. Comparing with Cowan's M3 distribution, the curve of modified model is closer to the empirical 
TABLE 1: Different models of proportion of free vehicles.

\begin{tabular}{lcc}
\hline Proposer & Model & Note \\
\hline Tanner (1962) [33] & $\alpha=1-\tau q_{c}$ & \\
Akcelik (1998) [34] & $\alpha=0.75\left(1-\tau q_{c}\right)$ & $Q_{c}<1600$ veh/h/lane \\
Sullivan (1997) [35] & $\alpha=0.8-0.0005\left(\frac{Q_{c}}{n}\right)$ & $A \in[6,9]$ \\
Brilon (1988) [36] & $\alpha=e^{-A q_{c}}$ & $b=2.5, \tau=2($ lane $=1), \tau=1.2($ lane $=2)$ \\
Akcelik and Chung (1994) [37] & $\alpha=e^{-b \tau q_{c}}$ & \\
Plank (1982) [38] & $\alpha=1-\tau^{2} q_{c}^{2}\left(3-2 \tau q_{c}\right)$ & \\
Hagring (1998) [39] & $\alpha=0.910-1.156 q_{c}$ & \\
\hline
\end{tabular}

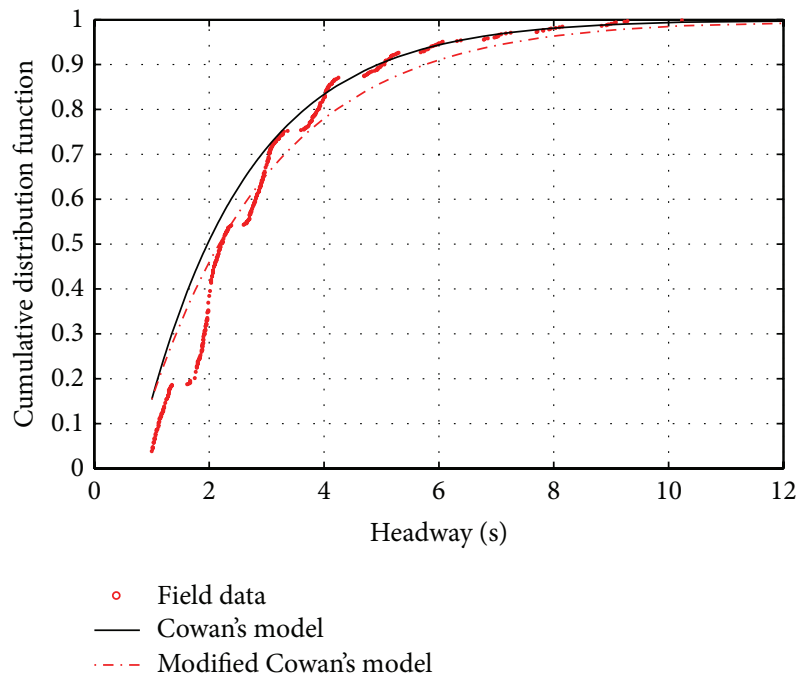

FIGURE 9: Comparisons of the different distribution models.

distribution curve, as shown in Figure 9. And from this, we can see that the modified model is better in the shorter headway than the original one.

In this part, the modified headway distribution was proved a better goodness of fit to the merging headway in high flow. Based on this equation, the derivation of capacity model of multilane approach is proposed next.

3.3. Model Derivation. From the above analysis, the impact of the limited priority on multilane roundabouts is expressed. Combined with the actual situation of multilane roundabouts, the derivation of capacity model is introduced in the following.

\section{Assumptions}

(1) The circulating flows obey the modification of Cowan's M3 model above.

(2) The drivers of entry approach have homogeneity and consistency.

(3) The lane-changing behavior is prohibited in the circulating areas.

(4) The circulating vehicles in different lanes are independent of each other and obey the same distribution.
In addition, the entry vehicles may be influenced by the exiting vehicles in the same leg at some roundabouts [4]. However, it only occurs in some certain situations; for example, the diameter of central island is small or the splitter island is too narrow. And field surveys showed that the vehicles would use the indicators when entered in or exited out from roundabouts in Changchun city, coupled with the larger island diameter; thus, the impact of exiting vehicles to entry capacity could be negligible in this research. Based on the above assumptions, the derivation process is listed as follows.

As per the extended process of Tanner's formula by Hagring at unsignalized intersection [39], $H(h)$ indicates the headway distribution, and $L(l)$ indicates the lag distribution. And the capital letter denotes the cumulative distribution function; the lowercase letter denotes the probability density function. $H_{i}$ is the headway distribution of lane $i$, and $H$ represents the headway distribution of $n$ lanes. Similarly, $L_{i}$ is the lag distribution of lane $i$, and $L$ represents the lag distribution of $n$ lanes. And the headway distribution of lane $i$ is expressed as (3), so the derivation process is following. lane $i$ is

As per Haight [45], the lag density function of circulating

$$
l_{i}(t)=q_{i}\left(1-H_{i}(t)\right) .
$$

Combining (3) and (4), one can obtain that

$$
l_{i}(t)=q_{i} \alpha_{i} C_{i} e^{-\lambda_{i}\left(t-\tau_{i}\right)}, \quad t \geq \tau_{i} .
$$

Thus one can obtain the lag distribution function of circulating lane $i$ :

$$
L_{i}(t)=1-\frac{q_{i} \alpha_{i} C_{i} e^{-\lambda_{i}\left(t-\tau_{i}\right)}}{\lambda_{i}}, \quad t \geq \tau_{i} .
$$

The relationship of lag distribution function between the whole circulating lanes and a single lane is [39]

$$
1-L(t)=\prod_{i}\left(1-L_{i}(t)\right), \quad t \geq \tau_{i} .
$$

Then combining (6) and (7), one can obtain the distribution of $n$-lane:

$$
L(t)=1-\prod_{i} \frac{q_{i} \alpha_{i} C_{i}}{\lambda_{i}} \prod_{i} e^{-\lambda_{i}\left(t-\tau_{i}\right)}, \quad t \geq \tau_{i} .
$$


Thus, the lag density function of $n$-lane is

$$
l(t)=\sum_{i} \lambda_{i} \prod_{i} \frac{q_{i} \alpha_{i} C_{i}}{\lambda_{i}} \prod_{i} e^{-\lambda_{i}\left(t-\tau_{i}\right)}, \quad t \geq \tau_{i} .
$$

Using the relationship of lag density function and the headway distribution headway once again, that is, combining (9) and (4), one can obtain that

$$
H(t)=1-\frac{\sum_{i} \lambda_{i}}{\sum_{i} q_{i}} \prod_{i} \frac{q_{i} \alpha_{i} C_{i}}{\lambda_{i}} \prod_{i} e^{-\lambda_{i}\left(t-\tau_{i}\right)}, \quad t \geq \tau_{i} .
$$

Using (7), (8), and (10), one can obtain that

$$
1-H(t)=\frac{\sum_{i} \lambda_{i}}{\sum_{i} q_{i}} \prod_{i}\left(1-L_{i}(t)\right), \quad t \geq \tau_{i} .
$$

As per Hagring, if every lane has one certain value, $\vec{t}=$ $\left(t_{1}, t_{2}, \ldots, t_{n}\right)$. And the distribution function can be expressed as

$$
H(\vec{t})=1-\frac{\sum_{i} \lambda_{i}}{\sum_{i} q_{i}} \prod_{i} \frac{q_{i} \alpha_{i} C_{i}}{\lambda_{i}} \prod_{i} e^{-\lambda_{j}\left(t_{j}-\tau_{j}\right)}, \quad t_{j} \geq \tau_{j}
$$

To simplify, define $\eta_{n}=\left(\sum_{i} \lambda_{i} / \sum_{i} q_{i}\right) \prod_{i}\left(q_{i} \alpha_{i} C_{i} / \lambda_{i}\right)$; let $t_{c i}$ and $t_{f i}$ denote the critical gap and the follow-up time of lane $i$. For an $n$-lane road, the probability of $k$ vehicles crossing all lanes is [39]

$$
\begin{aligned}
p(k)= & H\left(t_{c 1}+k t_{f 1}, t_{c 2}+k t_{f 2}, \ldots, t_{c n}+k t_{f n}\right) \\
& -H\left(t_{c 1}+(k-1) t_{f 1}, t_{c 2}+(k-1) t_{f 2}, \ldots, t_{c n}\right. \\
& \left.+(k-1) t_{f n}\right) .
\end{aligned}
$$

Combining (12) and (13), one can obtain that

$$
p(k)=\eta_{n} e^{-\sum_{j} \lambda_{j}\left(t_{c i}-\tau_{j}\right)} *\left(e^{-(k-1) \sum_{j} \lambda_{j} t_{f j}}-e^{-k \sum_{j} \lambda_{j} t_{f j}}\right) .
$$

According to the discrete theory [39], the general formula of capacity is

$$
\mathrm{CAP}=q \sum_{k=1}^{\infty} k p(k)
$$

Combining (14) and (15), one obtains that

$$
\mathrm{CAP}=\sum_{i} \lambda_{i} \prod_{i} \frac{\alpha_{i} q_{i} C_{i}}{\lambda_{i}} * \frac{e^{-\sum_{j} \lambda_{j}\left(t_{c j}-\tau_{i}\right)}}{1-e^{-\sum_{p} \lambda_{p} t_{f p}}} .
$$

Equation (16) is the general capacity model of multilane roundabouts, considering the limited priority.

3.4. Model Analysis. When $i=1$, we can obtain the capacity of single-lane roundabout; that is,

$$
\mathrm{CAP}_{1}=\frac{\alpha q C\left(1-e^{-\lambda(t-\tau)}\right)}{1-e^{-\lambda t_{f}}}
$$

By comparison, (17) is the same as Troutbeck's.

When $i=2$, assuming that there are different critical gaps and follow-up times, and equal minimum time $(\tau)$, so we can obtain that:

$$
\mathrm{CAP}=\left(\lambda_{1}+\lambda_{2}\right) \frac{\alpha_{1} \alpha_{2} q_{1} q_{2} C_{1} C_{2}}{\lambda_{1} \lambda_{2}} \frac{e^{-\left(\lambda_{1}\left(t_{c 1}-\tau\right)+\lambda_{2}\left(t_{c 2}-\tau\right)\right)}}{1-e^{-\left(\lambda_{1} t_{f 1}+\lambda_{2} t_{f 2}\right)}} .
$$

Generally, for the same lane in the approach, we can assume that there is an equal critical gap and follow-up time; then (18) can be simplified into

$$
\mathrm{CAP}_{2}=\frac{\left(\lambda_{1}+\lambda_{2}\right) \alpha_{1} \alpha_{2} q_{1} q_{2} C_{1} C_{2}}{\lambda_{1} \lambda_{2}} \frac{e^{-\left(\lambda_{1}+\lambda_{2}\right)\left(t_{c}-\tau\right)}}{1-e^{-\left(\lambda_{1}+\lambda_{2}\right) t_{f}}} .
$$

Similarly, for $i=3$, with the same critical gap and followup time and minimum headway, one can obtain

$$
\mathrm{CAP}_{3}=\sum_{1}^{3} \lambda_{i} \prod_{1}^{3} \frac{\alpha_{i} q_{i} C_{i}}{\lambda_{i}} * \frac{e^{-\sum_{1}^{3} \lambda_{j}\left(t_{c}-\tau\right)}}{1-e^{-\sum_{1}^{3} \lambda_{i} t_{f}}} .
$$

For an entry lane, if there is no constraint, the vehicles may enter in any circulating lane; thus, the entry capacity could be calculated as follows [46]:

$$
\begin{gathered}
q_{m}=\sum_{1}^{n} q_{m}^{i}, \quad x_{m}^{i}=\frac{q_{m}^{i}}{\operatorname{CAP}_{m}^{i}} \\
\mathrm{CAP}_{m}=\frac{q_{m}}{\sum_{1}^{i} x_{m}^{i}}
\end{gathered}
$$

where $m$ represent the lane at the approach, $i$ is the lane number which the entry vehicle needs to cross, and $x_{m}^{i}$ is the degree of saturation of stream $i$ in the lane $m$.

\section{Critical Gap Estimation}

In the gap-acceptance theory, the critical gap is the most key parameter, whose accuracy directly affects the entry capacity, which also could be seen in (16). Until now there are over thirty kinds of estimation methods, and we should select an appropriate estimation method against the multilane roundabout.

The maximum likelihood method was employed for estimating critical gap at TWSC intersections [47]. And for two major streams, Hagring [48] put forward a derivation process for the critical gap. Brilon et al. compared nine estimation methods for the critical gap and put forward four criteria of the reasonable prediction method. By comparisons, the maximum likelihood method and Hewitt's method are the best. In addition, Raff's method is used widely and easily, but it is sensitive to traffic volumes [49].

Combining with the above analysis, the maximum likelihood estimation (MLE) method and Raff's method are compared by field survey. In Raff's method, the mean critical headway is the intercept of the $F_{a}(t)$ and $1-F_{r}(t)$, where $F_{a}(t)$ is the cumulative distribution function (CDF) of accepted headway, and $F_{r}(t)$ is the CDF of rejected headway. Based on the assumption that one driver's critical gap is larger than 


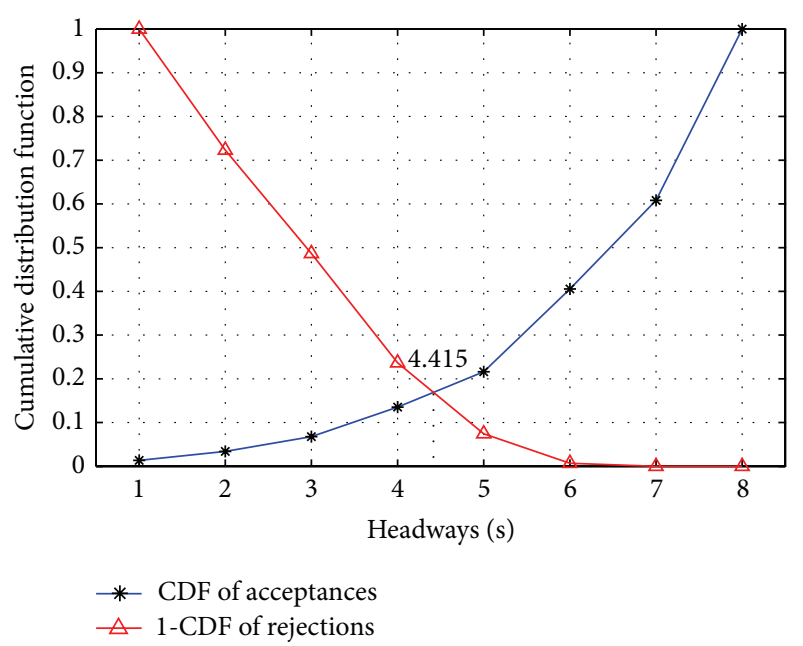

Figure 10: Mean critical gap estimated by Raff's method.

TABLE 2: Comparison of the two estimation methods.

\begin{tabular}{lcc}
\hline Method & \multicolumn{2}{c}{ Mean critical gap } \\
& Near lane & Far lane \\
\hline MLE method & & \\
$\quad$ Right lane & 4.581 & - \\
Left lane & 4.852 & 4.680 \\
Raff's method & & \\
Right lane & 4.415 & - \\
Left lane & 4.718 & 4.572 \\
\hline
\end{tabular}

his maximum rejected gap and smaller than his accepted gap, the MLE method was used to estimate. Assuming the drivers' critical gap obeys the log-normal distribution, Troutbeck [50] proposed a procedure for estimating the mean and standard variance of critical gap, shown as in the following:

$$
t_{c}=e^{\mu+0.5 \sigma^{2}}, \quad s^{2}=t_{c}^{2}\left(e^{\sigma^{2}}-1\right),
$$

where $\mu$ is the mean of distribution of logarithms of drivers' critical gap, $\sigma^{2}$ is the variance of distribution of logarithms of drivers' critical gap, and $s$ is the standard variance of drivers' critical gap.

The survey site is a two-lane roundabout in Changchun city, and the critical gap of right lane and left lane was estimated, respectively. Define the two circulating lanes as near lane and far lane, respectively; the former is adjacent to the entry lane, and the latter is near the central island. In the two entry lanes, the vehicles from the left lane may enter both circulating lanes, but the vehicles from the right lane only can enter the near lane. The result of right lane using Raff's method is shown as in Figure 10, and the similar method could be conducted to other lanes. Besides, the MLE method is also applied to the same lane, and the results were obtained as in Table 2.

From Table 2, it can be seen that the results of two methods are similar, and the big difference is 3.8\%. Considering that Raff's method is sensitive to traffic volume, however, the
MLE method is robust and, because of this, MLE method was selected for estimating the critical gap in the following.

\section{Model Comparisons}

By field survey at the multilane roundabout in Changchun city and by comparisons with three classical capacity models, the practicability of the proposed model was validated.

5.1. Analysis of Three Classical Models. Three existing capacity models were selected to compare with the proposed model. The first is Wu's capacity model, which is recorded in German Highway Capacity Manual (HBS) 2000 [2]. The second is the recommended model provided in the Highway Capacity Manual (HCM) 2010, which is drafted by FHWA [51]. And the third is Swiss model, which considers the effects of exiting flow and other influences [9]. The first and the third one could dispose one to three lanes, both circulating lane and entry lane. For the second one, the entry capacity of left lane is used in this paper due to the multilane being merely discussed, and it is aimed at two lanes. Combined with the above analysis, only one entry lane's capacity aiming at different number of circulating lane is discussed. The different models are shown as (23) to (24), respectively. Consider the following:

$$
\begin{gathered}
q_{e}=n_{e}\left(1-\frac{\tau \cdot q_{c}}{n_{c}}\right)^{n_{c}} \frac{1}{t_{f}} \cdot \exp \left(-q_{c} \cdot\left(t_{0}-\tau\right)\right) \\
q_{e, L}=1130 e^{\left(-0.75 \times 10^{-3}\right) q_{c}},
\end{gathered}
$$

where $q_{e}$ is the entry capacity, $q_{c}$ is the conflict flow rate of the circulatory lane, $n_{e}$ is the number of entry lanes, $n_{c}$ is the number of circulatory lanes, and $t_{0}=t_{c}-t_{f} / 2$, and $q_{e, L}$ is the capacity of left entry lane.

The Swiss model also depicted the entry capacity with two or three circulating lanes as follows:

$$
q_{e}=\left(1500-\frac{8}{9} \cdot q_{b}\right) \cdot \beta
$$

where $q_{b}=\gamma \cdot q_{c}+\alpha \cdot q_{a}$, in which $q_{a}$ is exiting flow; however, according to analysis above, it could be negligible in Changchun city, so the item could be simplified to $\gamma^{*} q_{c}, \gamma$ : $[0.6,0.8]$ for two circulating lanes (default $=0.66)$ and $[0.5$, $0.6]$ for three circulating lanes (default $=0.55), \quad \beta$ : $[0.9,1.1]$ for single entry lane (default $=1.0)$.

5.2. Comparisons of Capacity Models with Field Data. By video camera, two sites were observed in Changchun city; one has two circulating lanes, and another has three circulating lanes. Ignoring the different movement from one lane, the innermost entry lane was selected, from which the vehicles all enter into the innermost of the circulating carriageway. The follow-up times were extracted in one-minute intervals, when the persistent queue occurred. Besides, the critical gaps were estimated by MLE method. Applying the parameters into the above capacity models, the results are shown in Figure 11.

As can be seen from Figure 11(a), the proposed model has good consistency with Wu's model, which both have 
TABLE 3: Comparisons of different models with field data.

\begin{tabular}{lccccc}
\hline Type & RE & Proposed model & Wu's model & HCM 2010 model & Swiss model \\
\hline \multirow{3}{*}{ Two circulating lanes } & Max & $6.50 \%$ & $10.22 \%$ & $19.26 \%$ & $59.53 \%$ \\
& Min & $2.19 \%$ & $0.03 \%$ & $7.82 \%$ & $36.00 \%$ \\
& Average & $3.94 \%$ & $4.51 \%$ & $13.66 \%$ & $47.28 \%$ \\
\hline \multirow{2}{*}{ Three circulating lanes } & Max & $26.19 \%$ & $21.16 \%$ & - & - \\
& Min & $4.03 \%$ & $0.78 \%$ & - & $75.48 \%$ \\
& Average & $16.24 \%$ & $10.86 \%$ & - & $94.79 \%$ \\
\hline
\end{tabular}

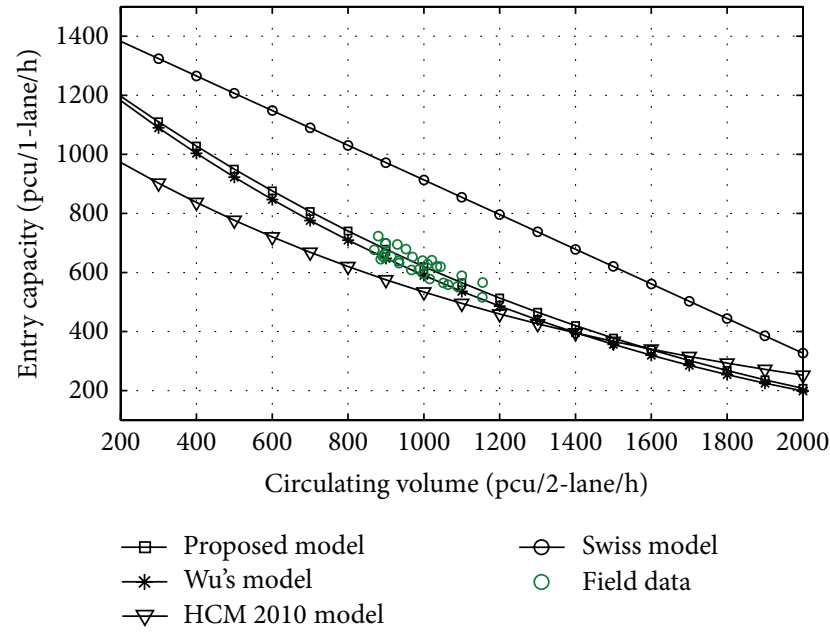

(a) Two circulating lanes

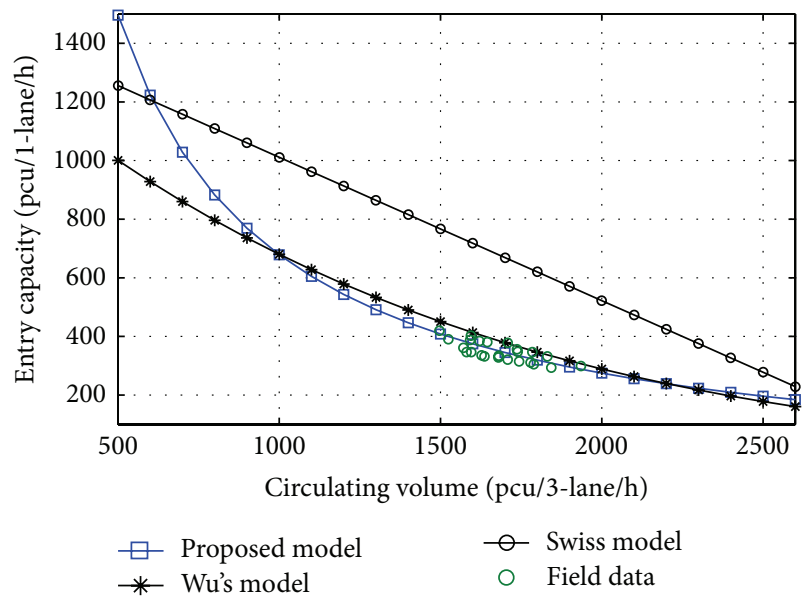

(b) Three circulating lanes

FIGURE 11: Comparison of the capacity models.

goodness of fit with field data. However, the Swiss model overestimated the entry capacity for two circulating lanes; the model of HCM 2010 boasts the opposite. In Figure 11(b), there is the same tendency with Figure 11(a). However, it could be seen that the proposed model vastly overestimated the capacity during low circulating volume.

Relative error (RE) method has been widely used in transportation analysis [52-57]. In this study, to compare the capacity models with the field data, we also apply this method, mathematically represented by

$$
\mathrm{RE}=\frac{\left|C_{\text {predict }}-C_{\text {field }}\right|}{C_{\text {field }}} \times 100 \%,
$$

where $C_{\text {field }}$ is the entry capacity by field observation and $C_{\text {predict }}$ is the predicted entry capacity.

The maximum value, the minimum value, and the average value of RE are computed on the conditions of two and three circulating lanes; the results were listed in Table 3 . The results showed that the proposed model and Wu's model have better prediction effects than other models. And the prediction to the two circulating lanes is better than the three lanes.

\section{Conclusions}

Considering the limited priority at multilane roundabouts and based on Troutbeck's research on this at the unsignalized intersection, the relation between limited priority factor and critical gap was discussed. Then, by improving the headway distribution of circulating streams after merging, the modified entry capacity model aiming at $n$-lane was derived based on gap-acceptance theory at multilane roundabout. By simply analyzing and comparing different estimation methods, the MLE method was selected to estimate the critical gap of entry lane in this study. Finally, three classical capacity models and the proposed model were compared with the filed data, that is, two-lane roundabout and three-lane roundabout, respectively. By comparisons with the RE of different models, Wu's model and the proposed model show better prediction performance.

In the case study, the vehicles from one entry lane all entered a definite circulating lane, and mixed purpose vehicles should be considered in the future research. Furthermore, O-D flows may affect the entry capacity [58], and the roundabout capacity on the whole may be more appropriate for application in engineering.

\section{Conflict of Interests}

The authors declare that there is no conflict of interests regarding the publication of this paper. 


\section{Acknowledgments}

This research was funded by the National Natural Science Foundation of China (nos. 51278520, 51108208, and 51278220), the Postdoctoral Science Foundation Funded Project of China (no. 2013T60330), the Fundamental Research Fund for the Central Universities of China (no. 201103146), and the Science and Technology Development Project of Jilin Province (no. 20130522121JH).

\section{References}

[1] A. Pochowski and E. J. Myers, "An analytical review of statewide roundabout programs and policies," Civil and Environmental Engineering, no. 2182, pp. 121-128, 2010.

[2] N. Wu, "A universal procedure for capacity determination at unsignalized (priority-controlled) intersections," Transportation Research B: Methodological, vol. 35, no. 6, pp. 593-623, 2001.

[3] H. R. Al-Masaeid, "Capacity and performance of roundabouts," Canadian Journal of Civil Engineering, vol. 26, no. 5, pp. 597$605,1999$.

[4] O. Hagring, "Derivation of capacity equation for roundabout entry with mixed circulating and exiting flows," Transportation Research Record, vol. 1776, no. 1, pp. 91-99, 2001.

[5] S. Tanyel, T. Baran, and M. Özuysal, "Determining the capacity of single-lane roundabouts in Izmir, Turkey," Journal of Transportation Engineering, vol. 131, no. 12, pp. 953-956, 2005.

[6] S. Tanyel, T. Baran, and M. Özuysal, "Applicability of various capacity models for single-lane roundabouts in Izmir, Turkey," Journal of Transportation Engineering, vol. 133, no. 12, pp. 647653, 2007.

[7] J. Dahl, "Capacity estimation for roundabouts with high truck volume using gap acceptance theory," Masters Abstracts International (Japan Association for Earthquake Engineering), vol. 50, no. 4, 2011.

[8] X. Qu, L. Ren, S. Wang, and E. Oh, "Estimation of entry capacity for single-lane modern roundabouts: case study in Queensland, Australia," Journal of Transportation Engineering, vol. 140, no. 7, Article ID 05014002, 2014.

[9] M. Blogg, E. Wemple, E. Myers et al., Appendixes to NCHRP Report 572: Roundabouts in the United States, Transportation Research Board, Washington, DC, USA, 2006.

[10] H. M. N. Al-Madani, "Capacity of large dual and triplelanes roundabouts during heavy demand conditions," Arabian Journal for Science and Engineering, vol. 38, no. 3, pp. 491-505, 2013.

[11] R. M. Kimber, "Gap-acceptance and empiricism in capacity prediction," Transportation Science, vol. 23, no. 2, pp. 100-111, 1989.

[12] E. Chung, W. Young, and R. Akcelik, "Comparison of roundabout capacity and delay estimates from analytical and simulation models," in Proceedings of the Australian Road Research Board, vol. 16, p. 369, Australian Road Research Board ltd, 1993.

[13] L. G. H. Fortuijn, "Turbo roundabouts: estimation of capacity," Transportation Research Record: Journal of the Transportation Research Board, vol. 2130, no. 1, pp. 83-92, 2009.

[14] R. Guo and B. Lin, "Gap acceptance at priority-controlled intersections," Journal of Transportation Engineering, vol. 137, no. 4, pp. 269-276, 2011.

[15] Z. K. Khatib, "Critical gap and follow-up time at multilane roundabout case study," in Proceedings of the 83th Annual
Meeting of the Transportation Research Board, Washington, DC, USA, 2004.

[16] A. Flannery and T. Datta, "Operational performance measures of American roundabouts," Transportation Research Record, vol. 1572, pp. 68-75, 1997.

[17] Y. Bie, Z. Liu, D. Ma, and D. Wang, "Calibration of platoon dispersion parameter considering the impact of the number of lanes," Journal of Transportation Engineering, vol. 139, no. 2, pp. 200-207, 2013.

[18] Y. Bie, D. Wang, and X. Qu, "Modelling correlation degree between two adjacent signalised intersections for dynamic subarea partition," IET Intelligent Transport Systems, vol. 7, no. 1, pp. 28-35, 2013.

[19] Y. Bie, D. Wang, and H. Qi, "Prediction model of bus arrival time at signalized intersection using GPS data," Journal of Transportation Engineering, vol. 138, no. 1, pp. 12-20, 2012.

[20] A. M. Hainen, "Roundabout critical headway measurement based on high-resolution event-based data from wireless magnetometers," in Proceedings of the Transportation Research Board 92th Annual Meeting, Washington, DC, USA, 2013.

[21] D. S. Abrams, C. D. Itzpatrick, Y. Tang, and M. A. Knodler, "A spatial and temporal analysis of driver gap acceptance behavior at modern roundabouts," in Proceedings of the Transportation Research Board 92nd Annual Meeting, Washington, DC, USA, 2013.

[22] C. Lee, "Prediction of capacity for roundabouts based on percentages of trucks in entry and circulating flows," in Proceedings of the Transportation Research Board 92th Annual Meeting, Washington, DC, USA, 2013.

[23] S. Mensah, S. Eshragh, and A. Faghri, "A critical gap analysis of modern roundabouts," in Proceedings of the 89th Annual Meeting of the Trans portation Research Board, 2010, Washington, DC, USA.

[24] A. Polus, "The effect of waiting times on critical gaps and an improved entry-capacity model at roundabouts," in Proceedings of the 81st Annual Meeting of the Transportation Research Board, Washington, DC, USA, 2002.

[25] F. Xu and Z. Z. Tian, "Driver behavior and gap-acceptance characteristics at roundabouts in California," Transportation Research Record, vol. 2071, no. 1, pp. 117-124, 2008.

[26] F. Xu, Driver Behavior and Gap Acceptance Studies at Roundabouts, University of Nevada, Reno, Nev, USA, 2007.

[27] R. Troutbeck, "Capacity of limited-priority merge," Transportation Research Record, vol. 1678, no. 1, pp. 269-276, 1999.

[28] R. J. Troutbeck and S. Kako, "Limited priority merge at unsignalized intersections," Transportation Research A: Policy and Practice, vol. 33, no. 3-4, pp. 291-304, 1999.

[29] D. F. Ma, X. L. Ma, S. Jin et al., "Estimation of major stream delays with a limited priority merge," Canadian Journal of Civil Engineering, vol. 40, no. 12, pp. 1227-1233, 2013.

[30] W. Wang and J. Q. Xu, "The study of new method of analyzing the roundabout capacity-the application of the queuing theory inn the roundabout analysis," Journal of Nanjing Institute of Technology, vol. 17, no. 1, pp. 119-128, 1987 (Chinese).

[31] Q. J. Xiang, W. Wang, B. Chen et al., "A study of the model construction for roundabout's capacity," China Journal of Hig hway and Transport, vol. 12, no. 4, pp. 69-72, 1999 (Chinese).

[32] R. J. Guo, Study on capacity of roundabouts based on gap acceptance theory [Ph.D thesis], Beijing Jiaotong University, Beijing, China, 2013, (Chinese). 
[33] J. C. Tanner, "A theoretical analysis of delays at an uncontrolled intersection," Biometrika, vol. 49, no. 1-2, pp. 163-170, 1962.

[34] R. Akcelik, "Roundabouts: capacity and performance analysis," ARRB Research Report ARR 321, ARRB Transport Research, Vermont, Australia, 1998.

[35] D. P. Sullivan and R. J. Troutbeck, "An exponential relationship for the proportion of free vehicles on arterial roads," Transportation Research Part A: Policy and Practice, vol. 31, no. 1, pp. 21-33, 1997.

[36] W. Brilon, "Recent developments in calculation methods for unsignalized intersections in west germany," in Intersections without Traffic Signals, pp. 111-153, Springer, Berlin, Germany, 1988.

[37] R. Akcelik and E. Chung, "Calibration of the bunched exponential headways," Road and Transport Research, vol. 3, no. 1, pp. 42-59, 1994.

[38] A. W. Plank, "Capacity of a priority intersection-two approaches," Traffic Engineering and Control, vol. 23, no. 2, pp. 88-92, 1982.

[39] O. Hagring, "A further generalization of Tanner's formula," Transportation Research B: Methodological, vol. 32, no. 6, pp. 423-429, 1998.

[40] R. T. Luttinen, "Properties of Cowan's M3 headway distribution," Transportation Research Record, vol. 1678, no. 1, pp. 189196, 1999.

[41] O. Hagring, N. M. Rouphail, and H. A. Sørensen, "Comparison of capacity models for two-lane roundabouts," Transportation Research Record: Journal of the Transportation Research Board, vol. 1852, no. 1, pp. 114-123, 2003.

[42] O. Giuffrè, A. Granà, and S. Marino, "Turbo-roundabouts vs roundabouts performance level," Procedia-Social and Behavioral Sciences, vol. 53, pp. 590-600, 2012.

[43] S. Tanyel and N. Yayla, "A discussion on the parameters of Cowan M3 distribution for Turkey," Transportation Research A: Policy and Practice, vol. 37, no. 2, pp. 129-143, 2003.

[44] L. Vasconcelos, A. B. Silva, Á. Seco, and J. Silva, "Estimating the parameters of Cowan's M3 headway distribution for roundabout capacity analyses," The Baltic Journal of Road and Bridge Engineering, vol. 7, no. 4, pp. 261-268, 2012.

[45] F. A. Haight, Mathematical Theories of Traffic Flow, Academic Press, New York, NY, USA, 1963.

[46] Z. Qu, Y. Duan, H. Hu, and X. Song, "Capacity and delay estimation for roundabouts using conflict theory," The Scientific World Journal, vol. 2014, Article ID 710938, 12 pages, 2014.

[47] Z. Tian, M. Vandehey, B. W. Robinson et al., "Implementing the maximum likelihood methodology to measure a driver's critical gap," Transportation Research A: Policy and Practice, vol. 33, no. 3-4, pp. 187-197, 1999.

[48] O. Hagring, "Estimation of critical gaps in two major streams," Transportation Research Part B: Methodological, vol. 34, no. 4, pp. 293-313, 2000.

[49] W. Brilon, R. Koenig, and R. J. Troutbeck, "Useful estimation procedures for critical gaps," Transportation Research Part A: Policy and Practice, vol. 33, no. 3, pp. 161-186, 1999.

[50] R. J. Troutbeck, Estimating the Critical Acceptance Gap from Traffic Movements, Physical Infrastructure Centre, Queensland University of Technology, 1992.

[51] Transportation Research Board, Highway Capacity Manual, National Research Council, Washington, DC, USA, 2010.

[52] X. Qu and Q. Meng, "A note on hotspot identification for urban expressways," Safety Science, vol. 66, pp. 87-91, 2014.
[53] X. Qu, E. Oh, J. Weng, and S. Jin, "Bus travel time reliability analysis: a case study," Proceedings of the ICE-Transport, vol. 167, no. 3, pp. 178-184, 2014.

[54] X. Qu, Y. Yang, Z. Liu, S. Jin, and J. Weng, "Potential crash risks of expressway on-ramps and off-ramps: a case study in Beijing, China," Safety Science, vol. 70, pp. 58-62, 2014.

[55] S. Jin, X. Qu, and D. Wang, "Assessment of expressway traffic safety using gaussian mixture model based on time to collision," International Journal of Computational Intelligence Systems, vol. 4, no. 6, pp. 1122-1130, 2011.

[56] S. Wang, Q. Meng, and Z. Sun, "Container routing in liner shipping," Transportation Research E: Logistics and Transportation Review, vol. 49, no. 1, pp. 1-7, 2013.

[57] J. Weng, Q. Meng, and X. Qu, "Vessel collision frequency estimation in the Singapore Strait," Journal of Navigation, vol. 65, no. 2, pp. 207-221, 2012.

[58] O. Hagring, "Effects of OD flows on roundabout entry capacity," in Proceedings of the 4th International Symposium on Highway Capacity, 2000. 


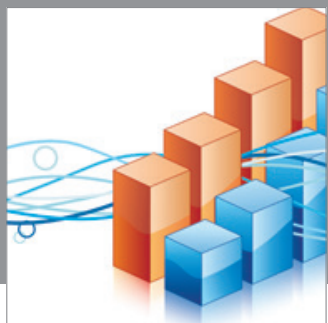

Advances in

Operations Research

mansans

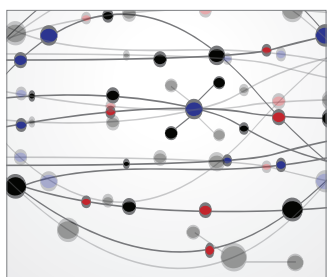

The Scientific World Journal
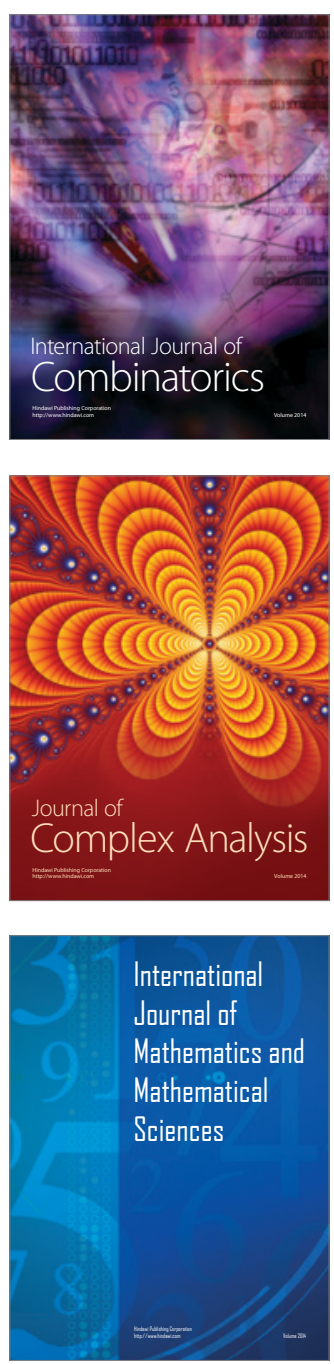
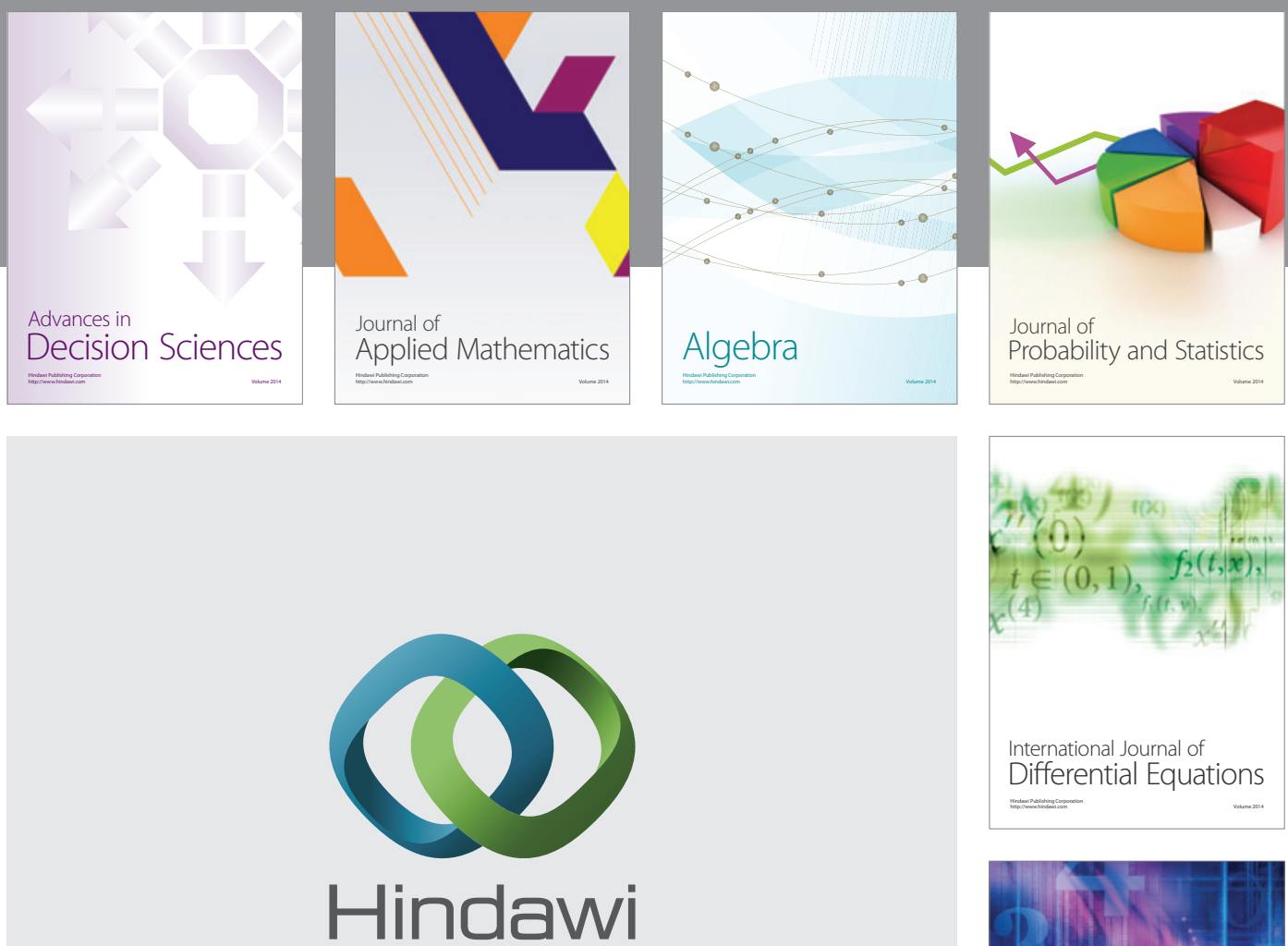

Submit your manuscripts at http://www.hindawi.com
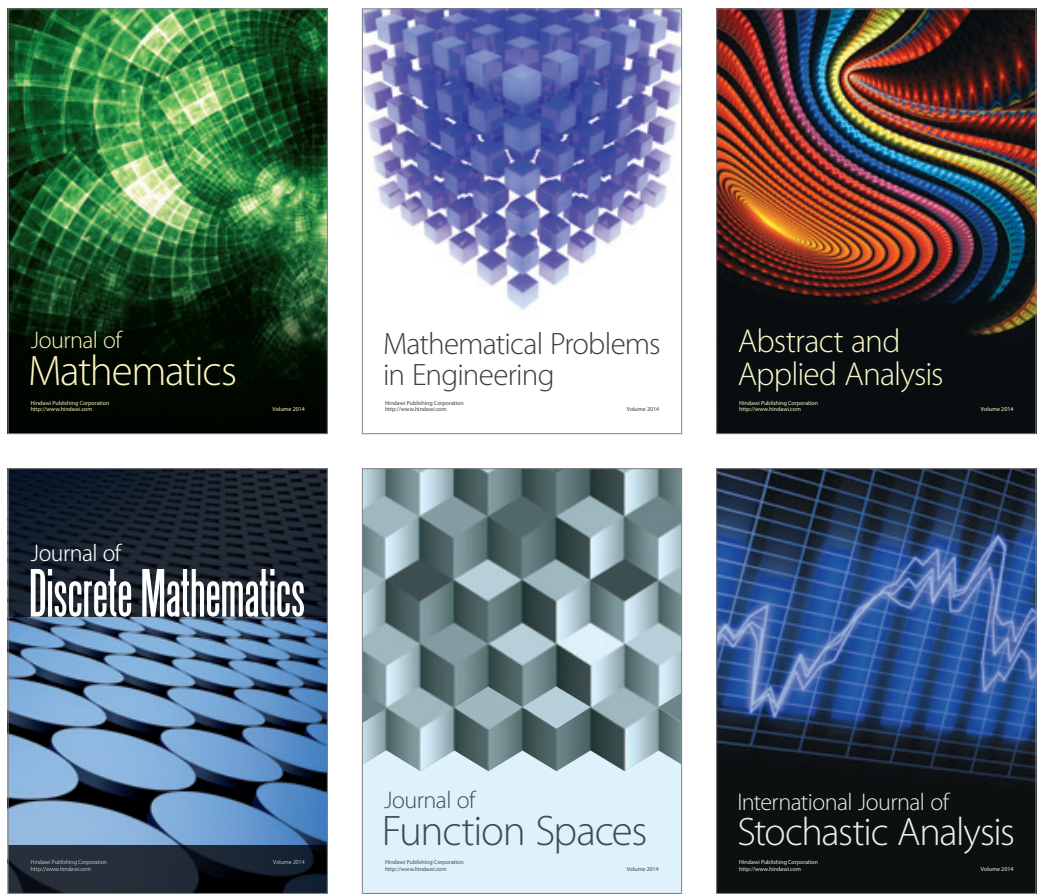

Journal of

Function Spaces

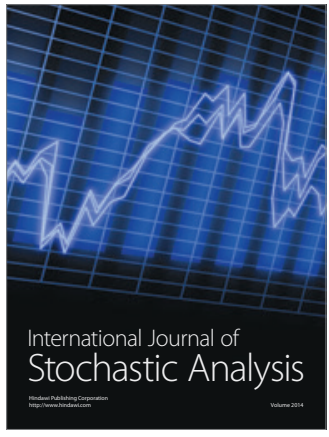

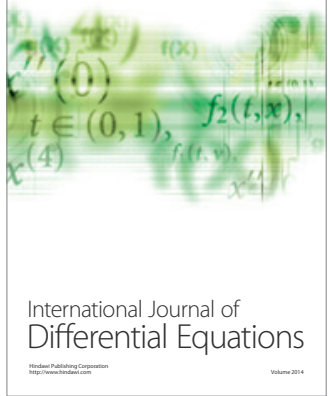
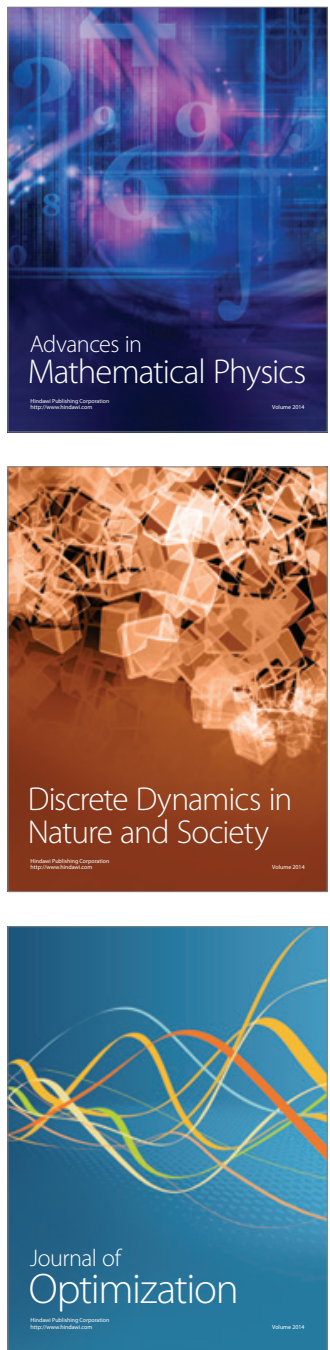